\title{
IDENTIFIKASI MODEL ARSITEKTUR JENIS POHON FAMILI LAURACEAE DI KAWASAN ARBORETUM SYLVA UNIVERSITAS TANUNGPURA PONTIANAK
}

\author{
(Architecture Models Identification Of Lauraceae Family In Arboretum Sylva Tanjungpura \\ University Pontianak)
}

\author{
Evlin Sitanggang, Togar Fernando Manurung, Slamet Rifanjani \\ Fakultas Kehutanan Universitas Tanjungpura Jl. Daya Nasional, Pontianak 78124 \\ Email : evlin.sitanggang@yahoo.co.id
}

\begin{abstract}
The tree architecture model is one of the important morphological features of the plants in characterizing each tree. Trees are plants with woody stems, deep roots, and have branches far from the ground and are more than 3 meters high (Hakim and Utomo 2003). trees are also one of the soft elements (softcape) that are very often used in the development of a site or landscape with a variety of unique characteristics. One of the unique characteristics of a tree is the dominant form of tree architecture formed by its canopy. This research was carried out at the Sylva Arboretum in Tanjungpura Pontianak for 3 weeks starting from July 42018 to July 24 2018 to observe and identify the architectural model of the lauraceae family tree. The research objective was to determine the architectural model of the Lauraceae family tree in Sylva Arboretum in Tanjungpura University Pontianak. The research method used is the exploration method, which is done by roaming, which means that observations can be made with visual and physical contact. Based on the results of the research and discussion, lauraceae family tree architecture models found in the Arboretum Sylva Area of Tanjungpura University Pontianak as many as four architectural models namely Rauh, Roux, Petit and Scarrone. The four architectural models were found in six species of trees, namely Ulin (Eusideroxylon zwageri), Medang sahung (Achiodaphne glabra), Medang pasir (Litsea eliptica), Medang bubur (Litsea resinosa), Medang sisik (Dehaasia firma), and Kayu manis (Cinnamomum iners).
\end{abstract}

Keyword: Family of Lauraceae, Model of Tree Architecture, Sylva Arboretum

\section{PENDAHULUAN}

Model arsitektur pohon merupakan salah satu ciri morfologi tumbuhan yang pentingartinya dalam pencirian masingmasing pohon. Konsep model arsitektur pohon berkembang sejaktahun 1970-an yang merupakan hasil sintesis dari konsep pada bidang teknik arsitektur, morfologitumbuhan dan taksonomi tumbuhan. Perkembangan konsep model arsitektur pada awalnya bertujuan untuk melengkapi ciri pembeda jenispohon tertentu. Pencirian tersebut bermanfaat untuk menambah konsep dasar pada bidangmorfologi tumbuhan dan taksonomi tumbuhan. Konsep model arsitektur pohon ini telah diterapkan pada bidang arsitektur pertamanan, pengembangan hutan kota dan konservasi tanah dan air (Oldeman Halle \& Tomlison, 1978). Famili Lauraceae merupakan salah satu famili yang memiliki genus dan jenis yang mempunyai manfaat baik hasil hutan berupa kayu dan hasil hutan bukan kayu. Pemanfaatan jenis pohon di famili 
ini ialah dilakukan secara luas oleh masyarakat. Pemanfaatan secara luas jenis famili Lauraceae perlu dilakukan identifikasi model arsitektur dari pohon yang belum diketahui model arsitekturnya Karena salah satu fungsi yang diperoleh dari analisa model arsitektur pohon adalah diketahuinya letak-letak organ generatif yang berfungsi sebagai pertimbangan untuk melakukan proses reproduksi suatu pohon.

Arboretum Sylva Universitas Tanjungpura Pontianak terdapat banyak spesies pohon dari berbagai famili. Salah satu famili yang ada yaitu famili Lauraceae. Famili ini banyak dimanfaatkan oleh masyarakat untuk berbagai keperluan. Tujuan Penelitian adalah untuk megetahui model arsitektur pohon famili Lauraceae di Kawasan Arboretum Sylva Universitas Tanjungpura Pontianak.

\section{METODE PENELITIAN}

Penelitian ini dilakukan pada Kawasan Arboretum Sylva Universitas Tanjungpura Pontianak, dengan waktu selama 3 minggu mulai dari tanggal 4 Juli 2018 sampai 24 juli 2018. Metode penelitian ini adalah metode survey. Teknik pengambilan data dilakukan dengan cara explorasi yang dilakukan dengan cara jelajah keseluruh bagian Arboretum Sylva Universitas Tanjungpura Pontianak.

Data penelitian terdiri atas :

a. Data primer yang diambil di lokasi penelitian berupa deskripsi pertumbuhan batang dan percabangan yang diamati pada masing-masing jenis pohon dan sketsa model arsitektur pohon dari masing-masing pohon yang diamati (percabangan batang dan tumbuhan). Pencatatan tersebut dilakukan pada semua jenis pohon famili Lauraceae yang ditemui pada lokasi penelitian sehingga data yang telah dicatat tersebut dapat membantu dalam mengenal nama jenisnya.

b. Data sekunder penunjang meliputi data iklim, keadaan umum lokasi, peta lokasi, dan literature yang relevan.

Data hasil penelitian dianalisis secara deskiptif, analisis data tersebut difokuskan pada percabangan batang yang meliputi :

1. Pola percabangan masing-masing pohon: (langsung/berirama, simpodial / monopodial) ;

2. Pola pertumbuhan batang, cabang dan tajuk: (simpodial / monopodial) ;

3. Differensiasi dari titik tumbuh pada cabang : (plagiotrof / ortotrof) dan

4. Letak organ generative : (lateral / terminal)

\section{HASIL DAN PEMBAHASAN}

A. Komposisi Jenis Pohon dan Model Arsitektur

Hasil penelitian diperoleh 6 (Enam) jenis pohon family Lauraceae. Sebanyak 6 jenis pohon tersebut ditemukan 4 jenis Model Arsitektur, keempat model tersebut yaitu Model Roux, Model Rauh, Model Petit dan Model Scarrone. Berdasarkan hasil penelitian dapat diketahui bahwa terdapat bermacam-macam model 
arsitektur pohon di Kawasan Arboretum Sylva Universitas Tanjungpura Pontianak. Model arsitektur ini akan berdampak bagi fungsi dan peran pohon yang ada di Area Kawasan Arboretum Sylva Universitas Tanjungpura Pontianak dan taman kota.

Tabel 1. Jenis Pohon Famili Lauraceae dan Model Arsitektur yang di temukan Di Arboretum Sylva Universitas Tanjungpura Pontianak (Lauraceae Family Tree Species Found in The Arboretum Sylva Tanjungpura University Pontianak).

\begin{tabular}{ll}
\hline No & Jenis Pohon \\
\hline 1 & Eusideroxylon zwagery \\
2 & Achiodaphne glabra \\
3 & Litsea elliptica \\
4 & Litsea resinonsa \\
5 & Dehaasia firma \\
6 & Cinnamomum iners \\
\hline B. Deskripsi Model Arsitektur Pohon \\
yang Ditemukan Di Arboretum Sylva \\
Universitas Tanjungpura Pontianak
\end{tabular}

Samingan (1982) menyatakan ada 21 bentuk atau model arsitektur pohon, Ke-21 model arsitektur didasarkan atas jenis-jenis yang terdapat di daerah tropika. Nama model arsitektur pohon tersebut diambil dari nama botani, misalnya Holttum (Botanisasi Inggris), Leewenberg (Botanisasi Belanda) dan sebagainya. Arsitektur pohon merupakan abstraksi dari genetik oleh suatu tumbuhan sejak mengawali pertumbuhannya, arsitektur pohon berbeda pengertian dengan pola pertumbuhan, habitus dan bentuk-bentuk tajuk. Arsitektur adalah bentuk dari produk akhir dari suatu pola perilaku pertumbuhan meristem apical, ukuran atau habitus bukan merupakan faktor pembeda karena pohon dengan herba dapat saja memiliki hasil akhir pola perilaku pertumbuhan yang sama. Deskripsi Model Arsitektur Tumbuhan Sebagai Berikut :

1. Model Roux

\author{
Model Arsitektur \\ Model Roux \\ Model Rauh \\ Model Rauh \\ Model Petit \\ Model Scarrone \\ Model Rauh
}

Model Roux merupakan model
arsitektur pohon dengan ciri-ciri batang bercabang, poliaksial atau pohon dengan beberapa aksis yang berbeda, dengan aksis vegetatif yang tidak ekuivalen dengan bentuk homogen, heterogen atau campuran tetapi selalu mempunyai perbedaan yang jelas antara batang dan cabang. Aksis vegetatifnya homogen (terdiferensiasi dalam bentuk aksis orthotropic atau aksis majemuk) percabangan akrotonik dalam membentuk batang, bukan konstruksi modular, sering kali dengan perbungaan lateral, batang monopodium dengan pertumbuhan batang serta percabangannya berlangsung secara kontinu. Percabangan flagiotropik bukan karena aposisi, monopidial atau simpodial karena subtitusi cabang dapat bertahan lama dan tidak menyerupai daun majemuk. Contoh pohon yang memiliki Model Arsitektur Roux yakni Pohon Ulin. 

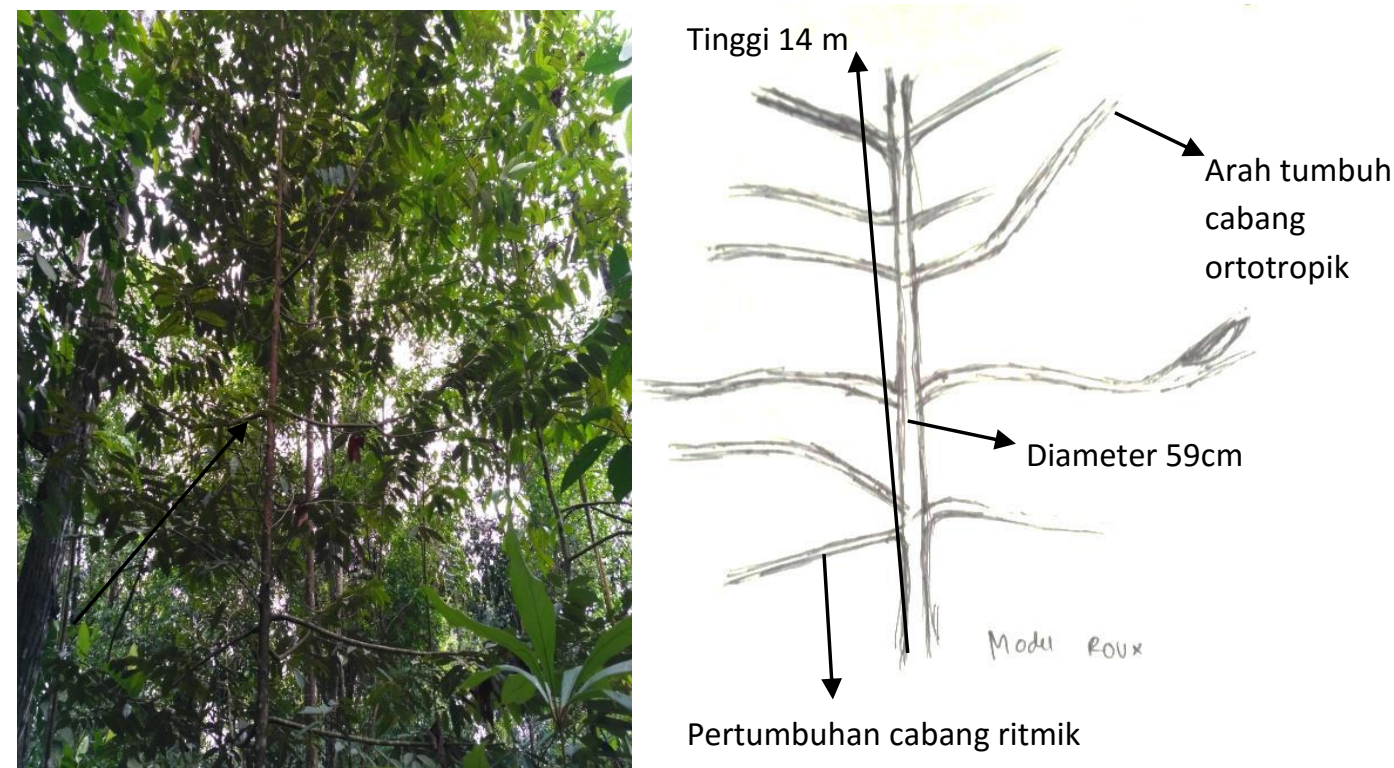

Gambar 1. Pohon Ulin (Eusideroxylon zwageri) dan Sketsa Arsitektur Model/ Percabangannya (Ulin (Eusideroxylon zwageri) and The Architecture Sketch).

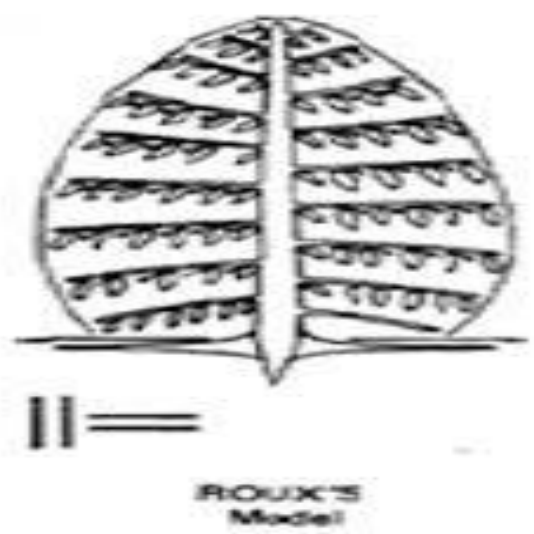

Sumber : Arsitektur Tumbuhan oleh Johan Iskandar dan Budiawati S. Iskandar Gambar 2. Arsitektur Pohon Model Roux ( Roux Architecture Model).

2. Model Rauh

Asal usul penamaan model arsitektur pohon ini diberikan oleh Rauh yang telah mendeskripsikan arsitektur pohon-pohon temperate (Rauh, 1939 dalam Halle et al. 1978). Arsitektur pohon model Rauh merupakan model arsitektur pohon yang memiliki batang monopodial, percabangan ritmik. Pola percabangan ini monopodial dan orthotrop. Pola percabangan ini berhubungan dengan batang perbungaannya, di mana umumnya lateral. Percabangan pada arsitektur pohon model Rauh berbentuk orthotropic. Bentuk ini akan meningkatkan aliran batang, karena cabang-cabang yang tumbuh vertikal berfungsi sebagai penampung air hujan, yang selanjutnya dialirkan ke batang. Fellizar

(1976) 
mengemukakan bahwa aliran batang merupakan bagian dari curah hujan yang ditahan oleh tajuk vegetasi, kemudian mengalir melalui batang dan kemudian akhirnya sampai kepermukaan tanah. Arsitektur pohon model Rauh umumnya ditemukan pada kelompok tumbuhan berbiji. Contoh pohon yang memiliki Model Arsitektur Rauh. yakni Pohon Medang.
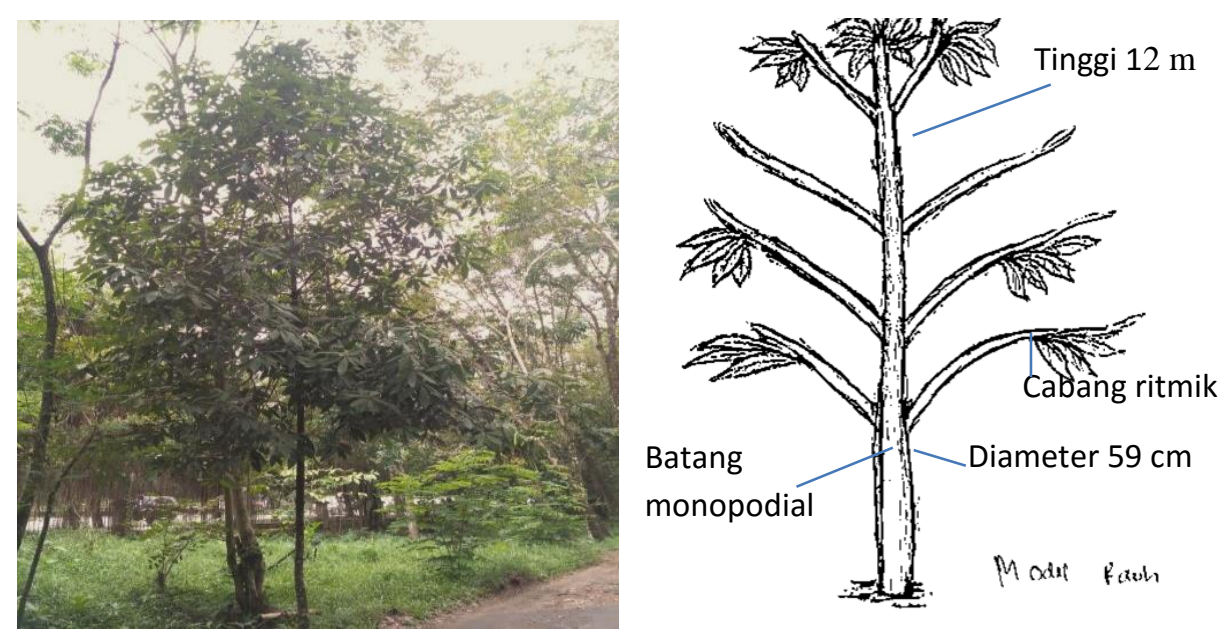

Gambar 3. Medang Sahung (Achiodaphne glabra) dan Sketsa Arsitektur Model/ Percabangannya (Medang Sahung (Achiodaphne glabra) and The Architectural Sketch).

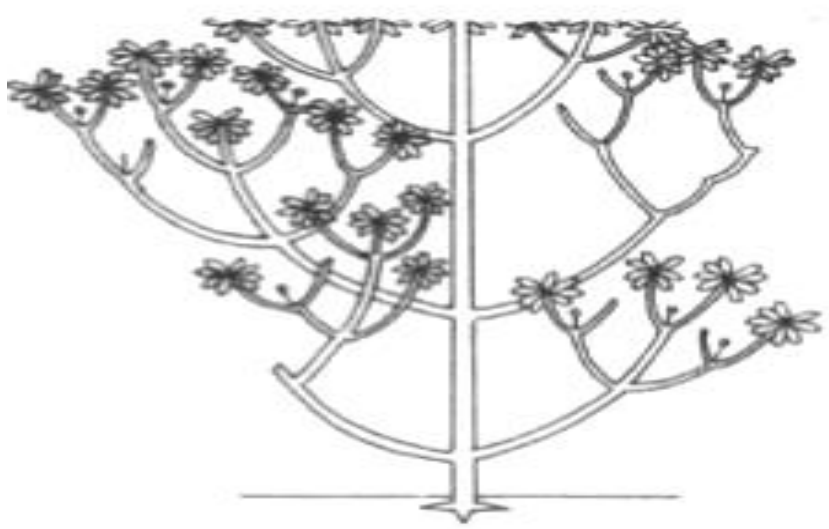

Sumber : Arsitektur Tumbuhan oleh Johan Iskandar dan Budiawati S. Iskandar Gambar 4. Arsitektur Pohon Model Rauh (Rauh Architecture Model).

3. Model Petit

Model arsitektur Petit merupakan salah satu model asitektur pohon dengan ciri batang bercabang, poliaksial, dengan aksis vegetatif tidak ekuivalen, homogen (terdiferensiasi dalam bentuk aksis ortotropik). Percabangan seluruhnya akrotonik dalam membentuk batang, konstruksi modular dengan cabang flagiotropik yang sedikit, modul umumnya memiliki perbungaan 
terminal yang berfungsi baik, pertumbuhan tingginya mengikuti bentuk dasar monopodial secara
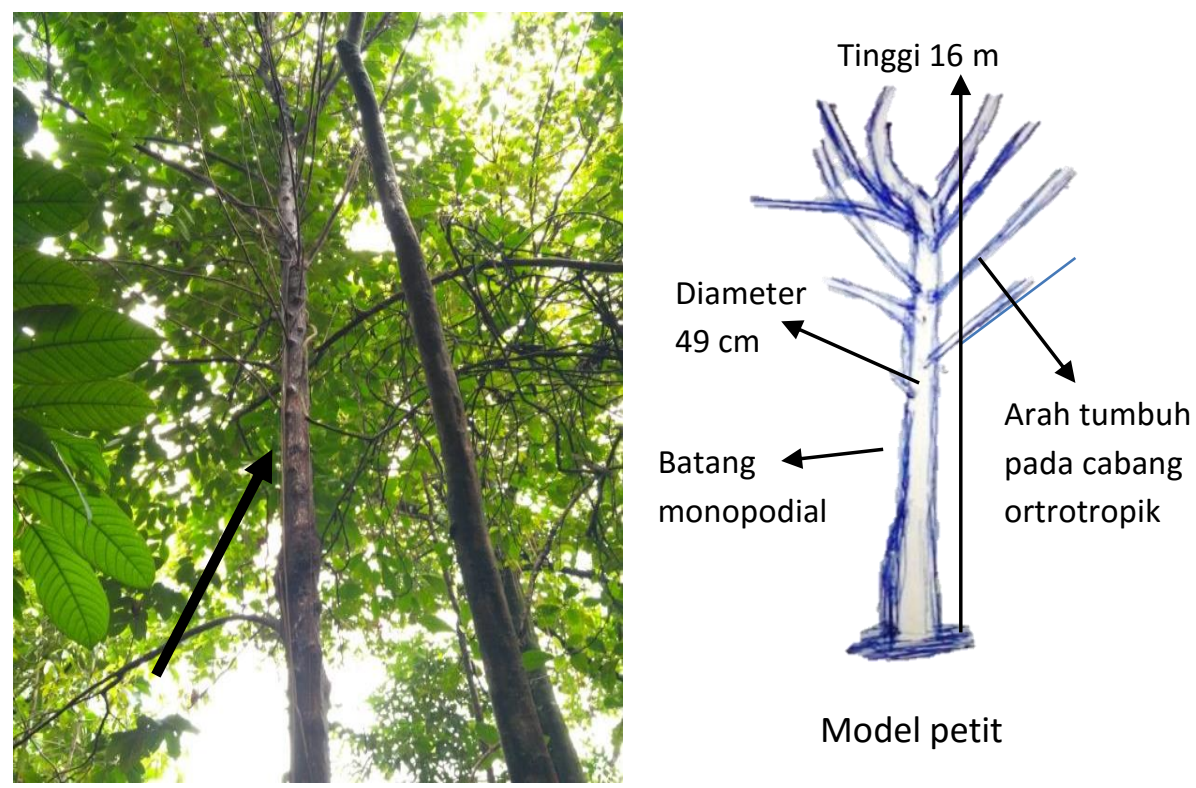

Model petit

Gambar 5. Medang Bubur (Litsea resinosa) dan Sketsa Arsitektur Model/ Percabangannya (Medang Bubur (Litsea resinosa) and The Architectural Sketch).

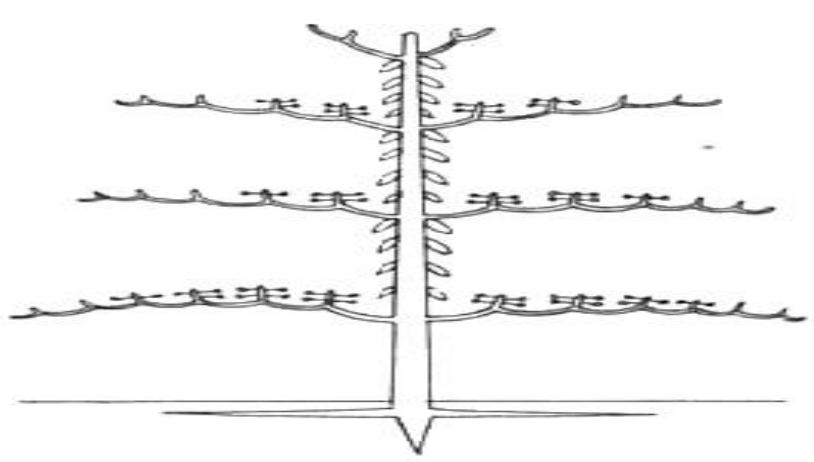

Sumber : Arsitektur Tumbuhan oleh Johan Iskandar dan Budiawati S. Iskandar Gambar 6. Arsitektur Pohon Model Petit (Petit Architectural Model).

4. Model Scarrone

Model Scarrone merupakan model arsitektur pohon yang memiliki batang monopodial dengan ciri-ciri batang bercabang seluruh axis orthotrop. Percabangan monopodial dengan perbungaan terminal, terletak pada bagian peri-peri tajuk, cabang simpodial nampak seperti konstruksi modular, batang dengan pertumbuhan tinggi ritmik. Contoh pohon yang memiliki Model Arsitektur Scarrone yakni Pohon Medang Sisik. 

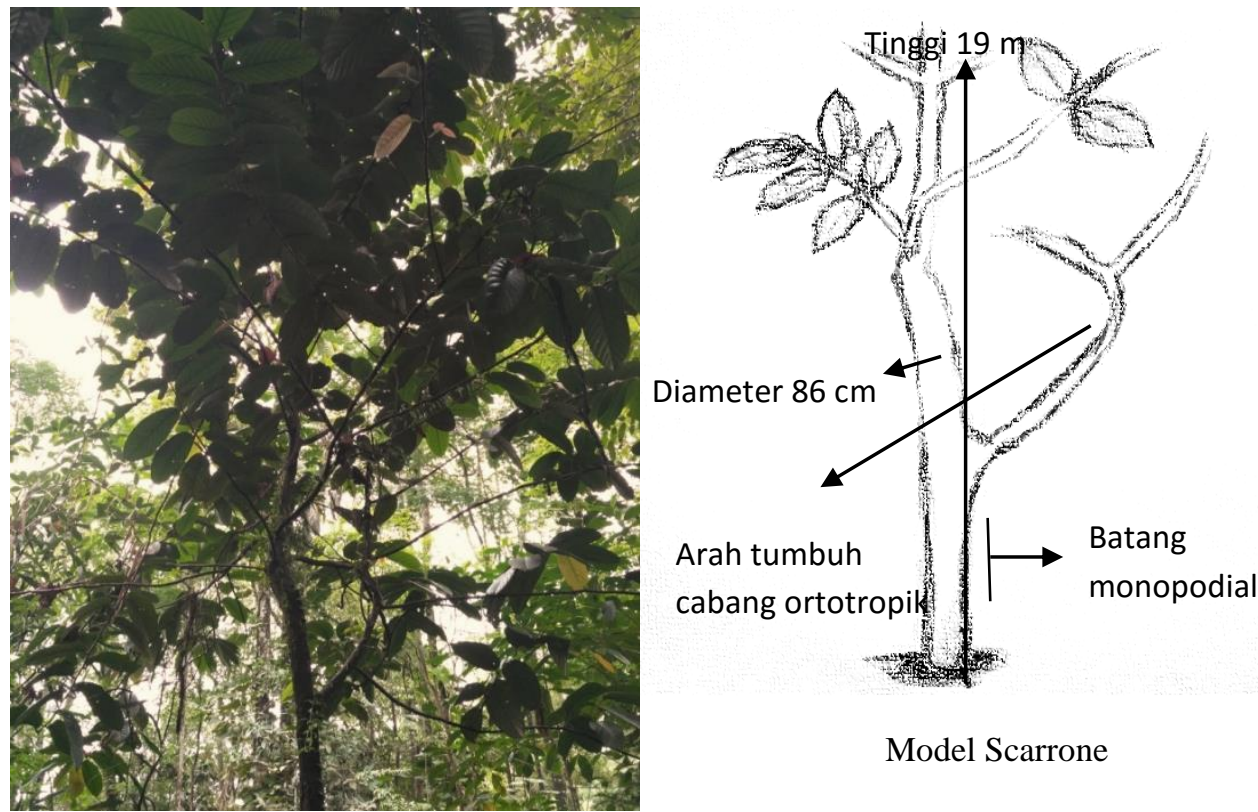

Gambar 7. Medang Sisik (Dehaasia firma) dan Sketsa Arsitektur Model/ Percabangannya (Medang Sisik (Dehaasia firma) and The Architectural Sketch).

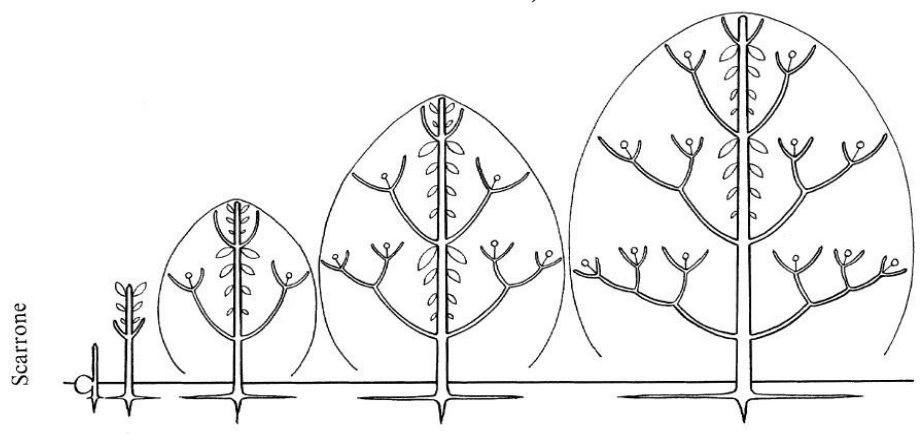

Sumber : Arsitektur Tumbuhan oleh Johan Iskandar dan Budiawati S. Iskandar Gambar 8. Arsitektur Pohon Model Scarrone (Scarrone Architectural Model).

\section{Deskripsi Jenis Pohon Family Lauraceae dan Model Arsitektur Pohon di Arboretum Sylva Universitas Pontianak.}

1) Ulin (Eusideroxylon Zwageri)

Merupakan model arsitektur Roux. Analisis struktur pada pohon belian memiliki batang utama monopodial dan memiliki model percabangan pada batang simpodial.Habitus pohon tinggi $\pm 20 \mathrm{~m}$ diameter $25 \mathrm{~cm}$. batang lurus berbanir, tajuk berbentuk bulat dan rapat serta memiliki percabangan yang mendatar dan memiliki buah yang keras salah satu pohon berkayu yang tumbuh secara alami di hutan tropis di Sumatera dan Kalimantan. Kayu teras pada bagian dalam pohon belian berwarna coklat 
kehitaman, sedangkan kayu gulbalnya berwarna coklat kekuningan. Daun pohon belian tersusun spiral, tunggal dengan pinggir rata berbentuk elips hingga bulat dengan ujung daun meruncing. Daun pohon belian memiliki panjang 14-18 cm dengan lebar 5-11 cm. Permukaan daun bagian atas kasar tanpa bulu, sedangkan bagian bawahnya berambut halus pada ibu tulang daunnya. Pohon ini umumnya tumbuh pada ketinggian $5-400 \mathrm{~m}$ di atas permukaan laut dengan medan datar sampai miring, tumbuh terpencar atau mengelompok dalam hutan campuran. Jenis pohon yang ditemukan di lokasi penelitian dan memiliki model arsitektur Roux.

2) Medang Sahung (Achiodaphne glabra)

Merupakan model arsitektur rauh. Analisis struktur batang monopodial, percabangan ritmik. Cabang monopodial dan ortotropik. Jadi, seluruh axis orthotropic dengan pertumbuhan tidak terbatas. Rhythmic atau tidak percabangan seluruh rhythmic. Karangan bunga axiller, tidak mengganggu pertumbuhan vegetatif. Habitus pohon tinggi $39 \mathrm{~m}$ diameter 12 $\mathrm{cm}$.

\section{3) Medang Pasir (Litsea elliptica)}

Merupakan model arsitektur rauh. Analisis struktur batang monopodial, percabangan ritmik. Cabang monopodial dan ortotropik. Jadi, seluruh axis orthotropic dengan pertumbuhan tidak terbatas. Rhythmic atau tidak percabangan selalu rhythmic. Karangan bunga axiller, tidak mengganggu pertumbuhan vegetatif. Habitus pohon tinggi 58,5 $\mathrm{m}$ diameter $14 \mathrm{~cm}$. daun berbentuk elips, berganti pada batang, panjang 8 hingga $13 \mathrm{~cm}$ dengan ujung tumpul. Venasi daun menonjol dan menarik di kedua sisi daun. Bunga berwarna hijau atau krem terbentuk dari bekas daun di branchlets atau di axils daun.

4) Medang Bubur (Litsea resinosa)

Merupakan model arsitektur petit. Analisis struktur pada pohon medang memiliki batang utama monopodial, pertumbuhan continous, orthotropic. Percabangan continous. Cabang plagiotropic dengan aposis dari module bunga di terminal. Habitus pohon tinggi $49 \mathrm{~m}$ diameter $16 \mathrm{~cm}$. daun berhadapan atau 3-4 vertikal, tangkai daun 2-5 cm, silinder pisau rhomboid, luas elips atau ovate, $8-19,5$ oleh 3,2-12 cm, seperti kulit, gundul, basis tumpul dengan jerawat kecil.

\section{5) Medang Sisik (Dehaasia firma)}

Merupakan model arsitektur scarrone. Analisis struktur pada pohon dehasia seluruh axis orthotropic. Batang monopodial, percabangan ritmik / rhythmic (pada herba tersusun terminal). Cabang dengan terbatas, cabang sympodial kompleks dan ortotropik. Habitus pohon $86 \mathrm{~m}$ diameter $19 \mathrm{~cm}$ daunnya berwarna hijau terang hingga hijau tua, teksturnya kasar mengkilap kedua sisi, batangnya kasar dan tidak beraturan. Daun dikelompokkan di ujung ranting. Bentuk perbungaan terbentuk di axils, umumnya tipis dengan banyak bracts dan beberapa bunga, biasanya tegak dan 
bercabang di sudut kanan. Spesies Dehaasia memiliki "bunga sempurna", memiliki bagian jantan dan betina.Buah lonjong, keras atau berdaging. Buahnya hitam-gelap dan mengkilap, umumnya merah, tetapi kadang-kadang berwarna kuning atau hijau.

6) Kayu Manis (Cinnamomum iners)

Merupakan model arsitektur rauh. Analisis struktur batang monopodial, percabangan ritmik. Cabang monopodial dan ortotropik. Jadi, seluruh axis orthotropic dengan pertumbuhan tidak terbatas. Rhythmic atau tidak, percabangan selalu rhythmic. Karangan bunga axiller, tidak mengganggu pertumbuhan vegetatif. Habitus pohon tinggi $\pm 15 \mathrm{~m}$, diameter dibawah $15 \mathrm{~cm}$, ciri daun berseling, bercabang, kulit batang kelabu dan licin, batang berwarna perang kekuning-kuningan, sederhana keras, berkilat, licin dan beraroma. Daunnya tersusun bertentangan, licin, tebal, bentuk bujur, panjang $8 \mathrm{~cm}$ hingga 16 $\mathrm{cm}$ dan lebar boleh mencapai sehingga $13 \mathrm{~cm}$, mempunyai tiga urat. Ia mempunyai bunga yang kecil dan berwarna kekuning-kuningan. Buah lebih kurang $10 \mathrm{~mm}$ panjang. Daunnya berbentuk mata tombak dengan panjang sekitar $20 \mathrm{~cm}$ dan lebar $5 \mathrm{~cm}$. Daun berwarna hijau pada bagian atas dan warna putih pada bagian bawah. Berbunga kecil dengan warna putih atau kekuning-kuningan yang membentuk gugusan pohon kayu.

\section{KESIMPULAN}

Berdasarkan hasil penelitian dan pembahasan maka :
1. Model Arsitektur pohon famili Laraceae pada Kawasan Arboretum Sylva Universitas Tanjungpura sebanyak 4 model arsitektur.

2. Keempat model arsitektur tersebut di jumpai pada enam jenis pohon yaitu Ulin (Eusideroxylon zwageri), Medang sahung (Achiodaphne glabra), Medang pasir (Litsea eliptica), Medang bubur (Litsea resinosa), Medang sisik (Dehaasia firma), dan Kayu manis (Cinnamomum iners).

\section{SARAN}

Informasi model arsitektur pohon pada famili lauraceae dapat dijadikan pertimbangan pemilihan pohon pada kegiatan pengelolaan kawasan, contohnya pada RTH (Ruang Terbuka Hijau) dan Hutan Kota.

\section{UCAPAN TERIMA KASIH}

Kami ucapkan terima kasih kepada pengelola Arboretum Sylva Universitas Tanjungpura Pontianak yang telah memberikan ijin dan bantuan fasilitas selama kegiatan penelitian di area Arboretum Sylva Universitas Tanjungpura Pontianak.

\section{DAFTAR PUSTAKA}

Arrijani, 2006. Model Arsitektur Pohon Pada Hulu DAS Cianjur Zona Sub-Montan Taman Nasional Gunung Gede Pangrango, Disertai. Bogor : Institut Pertanian Bogor.

Fellizer FP. 1976. Stemflow Characteristics of parashore Plicata, Pentacme contorta and 
Arengapinannta. A Philippine Science J forest. 2:85-92.

Forest Watch Indonesia dan Global Watch. 2011. Potret Keadaan Hutan Indonesia, Bogor.

Forman RTT dan Gordon M. 1986. Landscape Ecology. Canada: John Wiley.

Hasanuddin. Morfologi Tumbuhan, Banda Aceh: Ar- Raniry Press, 2004.

Hakini R, Utomo H. 2003. Komponen Perancangan Arsitektur Lanskap. Jakarta (ID): Bumi Aksara.

Halle F, Oldeman RAA. and Tomlinson PB. 1978. Tropical Trees and Forest an Acrhitecture Analysis, Springer Verlag. Berlin Heidelberg, Newyork.

Keputusan Pemerintah No. 11 tahun 2011. Penetapan Hutan Kota, Pontianak.

Muttaqien Z, Santoso P, dan Kusmoro J, 2008. Studi Vegetasi Hutan Hujan Tropis Pegunungan di Gunung Manglayang Jawa Barat. Widyariset Journal, 11(2):157-164.

Samingan T. 1982. Dendrologi. Jakarta : PT. Gramedia. 